Review

\title{
Biology of IL-27 and its Role in the Host Immunity against Mycobacterium Tuberculosis
}

\begin{abstract}
Abualgasim Elgaili Abdalla1,2, Qiming Li1 ${ }^{1}$, Longxiang Xie ${ }^{1}$, Jianping Xie ${ }^{1 凶}$
1. Institute of Modern Biopharmaceuticals, State Key Laboratory Breeding Base of Eco-Environment and Bio-Resource of the Three Gorges Area, Key Laboratory of Eco-environments in Three Gorges Reservoir Region, Ministry of Education, School of Life Sciences, Southwest University, Beibei, Chongqing 400715, China.

2. Department of Clinical Microbiology, College of Medical Laboratory Sciences, Omdurman Islamic University, Omdurman, Khartoum, Sudan.
\end{abstract}

$\triangle$ Corresponding author: Jianping Xie. E-mail: georgex@swu.edu.cn; Tel\&Fax: 862368367108

(c) Ivyspring International Publisher. This is an open-access article distributed under the terms of the Creative Commons License (http://creativecommons.org/ licenses/by-nc-nd/3.0/). Reproduction is permitted for personal, noncommercial use, provided that the article is in whole, unmodified, and properly cited.

Received: 2014.09.02; Accepted: 2014.11.16; Published: 2015.01.05

\begin{abstract}
IL-27, a heterodimeric cytokine of IL-12 family, regulates both innate and adaptive immunity largely via Jak-Stat signaling. IL-27 can induce IFN- $\gamma$ and inflammatory mediators from T lymphocytes and innate immune cells. IL-27 has unique anti-inflammatory properties via both $\mathrm{Trl}$ cells dependent and independent mechanisms. Here the role and biology of IL-27 in innate and adaptive immunity are summarized, with special interest with immunity against Mycobacterium tuberculosis.
\end{abstract}

Key words: IL-27; IL-27Ra; IL-12 family; Mycobacterium tuberculosis; Immunity

\section{Introduction}

Tuberculosis remains a leading cause of death worldwide which afflicts approximately one-third of the world's population and claims a death toll around 1.2 million annually [1].

Mycobacterium tuberculosis $(M t b)$ is an unusual facultative intracellular pathogen which multiplies within macrophage [2]. Macrophages are crucial for the innate and adaptive immune response to $M t b$ because of their potent antimicrobicidal activities, antigens-presenting abilities, secretion of inflammatory mediators such as the IL-12 family of cytokines [3, 4], and their role in granuloma formation to control the pathogen [5-7]. However, $M t b$ can persist within granuloma lifelong without clinical symptoms $[3,4$, 8]. In-depth understanding of the underlying molecular mechanisms can inspire better drug design and treatment of TB.

The interleukin-12 (IL-12) family, including IL-12, IL-23, IL-27 and IL-35, are important for TB pathogenesis and control, which can regulate the Th1 response $[9,10]$.

Interleukin-27 (IL27) was first discovered in 2002 as a new member of the IL-12 cytokine family [11]. It is a heterodimer, comprised of p28 and EBI3 subunits that are structurally similar to the p35 and p40 subunits of IL-12 [12].

IL-27 is largely secreted from activated antigen-presenting cells (APCs) such as macrophages and Dendritic cells (DCs) [13-15] (Figure 1). The receptor of IL-27 consists of two subunits: IL-27Ra and gp130. Both subunits are essential [16-18] for activating Janus Kinase (Jak) and Transcription factor (Stat). Specifically, Statland Stat 3 are predominant mediators of IL-27 effects (figure 2) $[19,20]$. IL-27 can mediate Th1 cells differentiation and proliferation [17, 18]. IL-27 has potent antitumor activities by activation of cytotoxic T lymphocytes CD8+ T cells [21-25], Natural killer (NK) cells [26-28], NK T cells [28] and anti-angiogenic factors $[29,30]$. However, IL-27R signaling was demonstrated to be involved in the potent antagonizing of Th1, Th2 and Th17 inflammatory responses [31-33] and agonist of $\operatorname{Tr} 1$ cell response [34, 35]. IL-27 can ameliorate symptoms of autoimmune diseases in preclinical studies [33, 36, 37]. 
The expression level of IL-27 in granuloma suggested a role in tuberculosis [38]. The elevated level of IL-27 in tuberculous pleural fluid suggested a potential biomarker for tuberculous pleurisy diagnosis [39, 40]. IL-27 level might be manipulated to benefit pathogen [41-43].

\section{Molecular characteristics of IL-27}

IL27 is a heterodimeric cytokine consisting of p28 and Epstein-Barr virus induced gene 3 (EBI3) subunits $[16,44]$. EBI3 expression is high in human B lymphoblast cell lines transformed in vitro by EBV, activated APCs and placental syncytiotrophoblasts $[16,45]$. EBI3 is a $34-\mathrm{kDa}$ glycoprotein similar to the p40 subunits of IL-12 [46]. The EBI3 reversibly binds to IL-12p35-related subunit, namely p28, to form heterodimeric cytokine IL-27[46, 47]. The connection between p28 and EBI3 is labile and these subunits can be secreted independently [16]. EBI3 is also capable of binding to the IL-12p35 to form IL-35 [48]. The human p28 gene encodes a $24.5 \mathrm{kDa}$ polypeptide [16]. The p28 is structurally similar to an IL-6/IL-12 family, composed of a long chain of four a helix bundle named A-D from the $\mathrm{N}$ terminus to the $\mathrm{C}$ terminus[49]. The polypeptide loop connecting the p28 C and D a helices contains a stretch of polyglutamic acids (poly-E) unique among helical cytokines and is highly conserved [50]. The p28 alone can suppress IL-27 mediated Th1 responses [51] and IL-6 mediated signaling [52]. These data suggest a regulatory role of p28 in
IL-27-mediated immune response.

A polymorphism $(-964 A>G)$ in the p28 promoter has been noted in certain diseases such as asthma [53], inflammatory bowel diseases [54], chronic obstructive pulmonary disease[55], and epithelial ovarian cancer [56], which seems to be associated with an increase in disease susceptibility. However, the effects of SNPs on the expression of IL-27 remain elusive.

IL-27 is mainly produced by activating APCs such as DCs and macrophages (figure 1). Macrophages-stimulated with TLRs agonists, (polyinosinic: polycytidylic acid (poly (I:C)), Lipopolysaccharide (LPS), or R848 can induce both subunits of IL-27 [13]. It has been reported that $\mathrm{p} 28$ production is completely dependent on the TLR4-associated myeloid differentiation factor 88 (MyD88) mediated pathway and partially dependent on NF- $\kappa \mathrm{Bc}-$ Rel transcription factor [14]. MyD88 also regulates p28 expression through binding of AP-1/c-Fos to the p28 promoter in both human and mouse macrophages. However, the binding of c-Fos to the p28 promoter can be blocked by overexpression of p38 MAPK [57]. In addition, TLR4 can induce the expression of p28 subunit through activating the TIR domain-containing adaptor inducing IFN- $\beta$ (TRIF) and IFN regulatory factor 3 (IRF3) pathways [58]. TLR2, TLR4, and TLR9-associated MyD88 are required for the induction of EBI3 expression through binding of NF-kB subunits (p50/p65) and PU.1 to the EBI3 promoter [59].

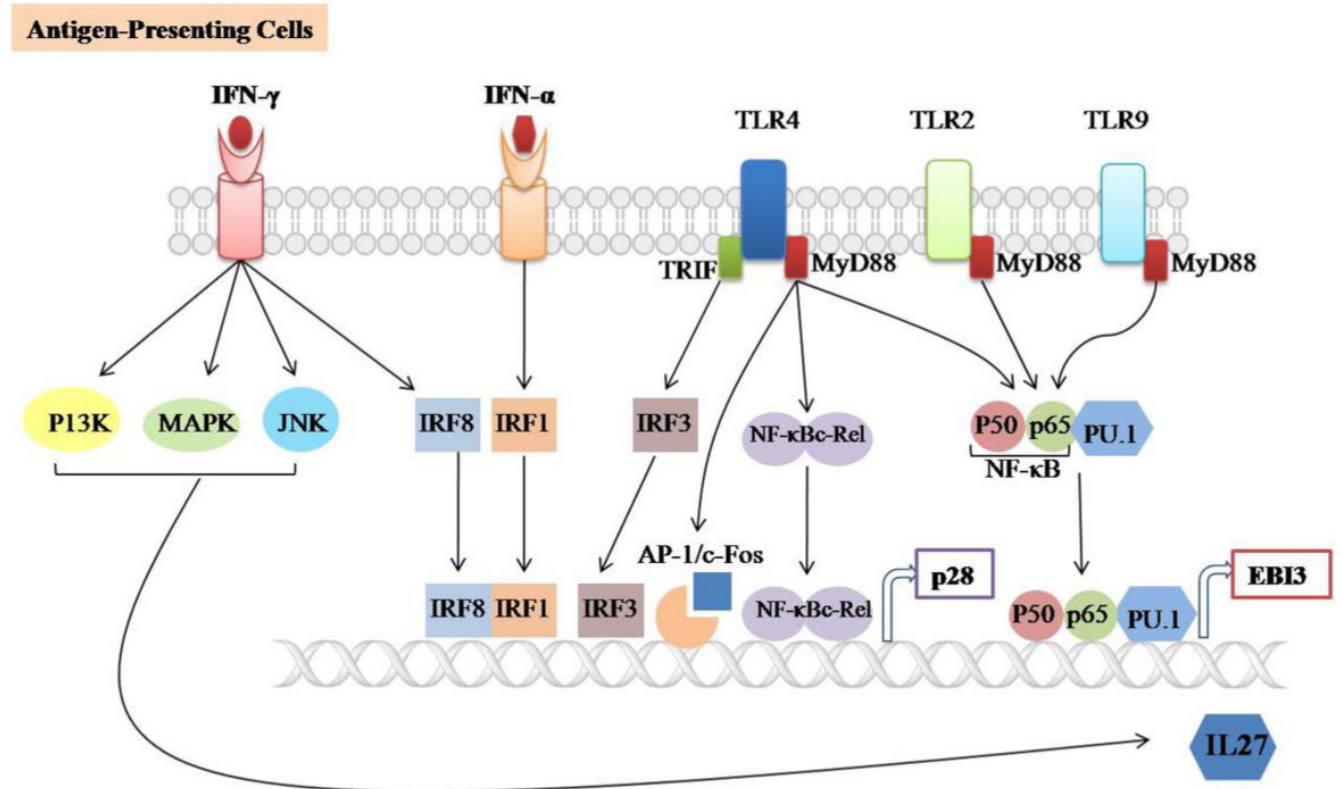

Figure 1. Signaling involved in IL-27 expression. IL-27 is largely produced by Antigen-presenting cells (APCs) such as Dendritic cells (DCs) and macrophages upon stimulation with TLRs agonists, IFN- $\alpha$, IFN-y or microbial infections. It consists of two subunits (p28/EBI3) which are expressed independently. TLR2, TLR4 and TLR9-associated MyD88 can induce EBI3 expression through the binding of NF-кB subunits (p50/p65) and PU.1 to the EBI3 promoter. TLR4-associated MyD88 induces 28 expression through binding of NF-KB-c-Rel and AP-1/c-Fos to the p28 promoter, TLR4-associated TRIF induces p28 expression by binding of IRF3 to the p28 promoter. The IFN- $\alpha$ and IFN- $\gamma$ induces p28 expression through the binding of IRF3 and IRF8 to the p28 promoter, respectively. In addition, IFN- $\gamma$-mediated IL-27 instead of IL-27p28 gene expression is positively regulated by the C-Jun N-terminal kinases (JNK), mitogen-activated protein kinases (MAPKs) and the phosphoinositide 3-kinase (PI3K). 

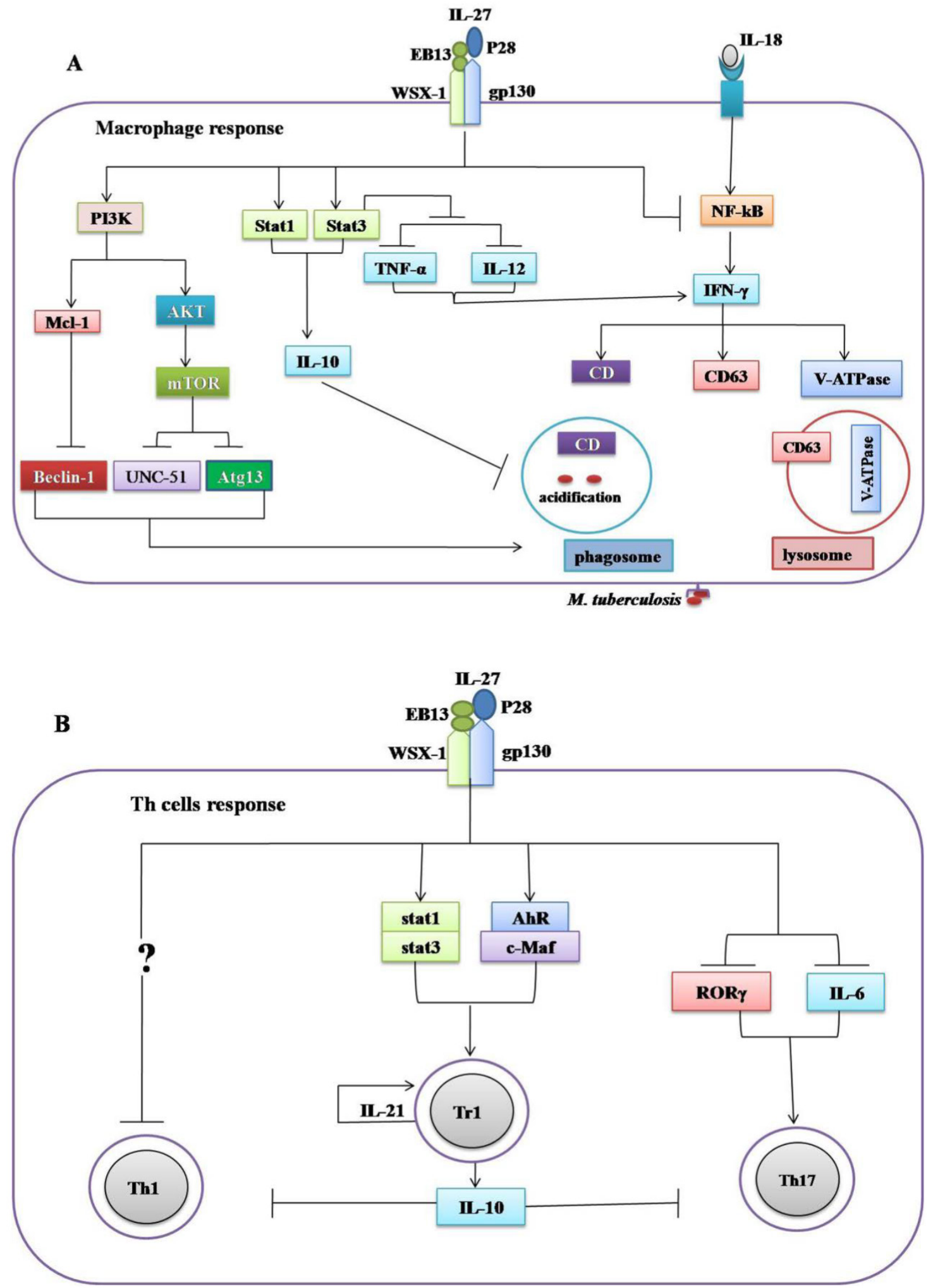

Figure 2. Regulatory role of IL-27 in the immune response against Mycobacterium tuberculosis. (A) IL-27 induced by Mtb infection modulates macrophage response. IL-27 inhibits autophagy by inducing negative regulator factors of autophagy mTOR and Mcl-1 through PI3K/AKT and PI3K, respectively. IL-27 induces IL-10 production through Stat I/Stat3, which in turn blocks phagosomal maturation. It also suppresses TNF- $\alpha$ and IL-12 via Stat3 and both cytokines required for augmenting IFN- $\gamma$ production by macrophages. In addition, IL-27 targeting NF-kB to inhibit IL-18 mediated IFN- $\gamma$ production. Suppression of IFN- $\gamma$ led to down-regulation of V-ATPase and CD63 and Capethsin D (CD) and subsequently suppression of phagosomal acidification. (B) IL-27 induced IL-10-producing type 1 regulatory T cells $(\mathrm{Trl})$ cell via Stat1/Stat3 and AhR/c-Maf pathway, which in turn suppress Thl and Th17 cells. IL-27 directly inhibits Th17 cells by inhibiting ROR-Y expression and IL-6 signaling. 
IFN-alpha can promote the production of IL-27 by enhancing the expression and binding of IRF-1 to the IFN-stimulated response element (ISRE) in the p28 gene promoter [13]. Likewise, IFN- $\gamma$ induced IRF-8 expressions can upregulate p28 gene transcription in synergy with IRF-1 [15]. IFN-ץ can selectively induce IL-27 expression via activating the C-Jun N-terminal kinases (JNK), MAPKs and the phosphoinositide-3-kinase (PI3K) signaling in primary human monocyte[60]. Many molecular details of the negative regulation of IL-27 expression remain to be determined.

\section{IL-27 signaling pathways}

IL-27R is indispensable for the IL-27 signaling. IL-27R consists of the class I cytokine receptor family (TCCR) (also known as WSX-1) and gp130 [16-18]. IL-27R is expressed in various cell types including naïve $\mathrm{T}$ cells, NK cells, activated $\mathrm{B}$ cells, monocytes, dendritic cells, activated endothelial cells, and mast cells [61]. IL-27 induced intracellular signaling involves phosphorylation of different isoforms of Jak and Stat, which varies with immune cell types: Jak1, Jak2, Tyrosine kinase 2 (Tyk2), Stat1, 2, 3, 4 and Stat5 in naïve CD4 T cells [62], Jak-1, Stat1, Stat-3 and Stat5 in NK cells[61, 63] , Stat1, Stat3, and NF-kB activation in monocytes [20], and Stat-3 in mast cells [64]. Interestingly, the effect of the IL-27 can be both pro-inflammatory and anti-inflammatory via same Stat1/Stat3 signaling.

The pro-inflammatory role of IL-27 as key inflammatory mediator for Th1 differentiation and IFN- $\gamma$ production has been intensively explored [16, 63 , 65]. Stimulation of Th0 in the presence of IL-27 induces the expression of the key signature Th1 cytokine IFN- $\gamma$ via up-regulating of the transcription factor T-bet and IL-12R $\beta 2$ chain which is essential for responding to IL-12 and the differentiation of a Th1 phenotype [61, 62, 65]. This effect of IL-27 on Th cell depends on multiple transcription factors such as Stat- 1 and Stat-3 [61, 62, 65]. In vivo studies demonstrated the role of IL-27 in Th1 responses. In this context, it was shown that WSX-1-/- mice were more susceptible to Leishmania major infection and impaired IFN- $\gamma$ production [17]. Similarly, reduced Th1 responses and IgG2a production was demonstrated in WSX-1-deficient mice infected with Listeria monocytogenes [18]. Moreover, it was shown that IL-27R signaling is vital in vivo for the IFN- $\gamma$ production by CD8+ T cells [66]. IL-27 can enhance the proliferation of naïve CD8+ T cells and IFN- $\gamma$ and granzyme B production dependent on Stat1 and Stat3 [22].

IL-27 can stimulate human monocyte to express TLR4 through activation of Stat-3, and NF- $\mathrm{kB}$ which subsequently respond to LPS-inducing IL-6, TNF- $\alpha$,
MIP-1a, and MIP-1 $\beta$ expression [67]. IL-27 increased the production of nitric oxide from peritoneal macrophages via activation of Stat-1, NF-kB and MAPKs [68]. IL-27 also enhanced monocyte derived dendritic cells (moDCs) to express IL-27, IL-8, CXCL10, chemokine receptor (CCR1), IFN-stimulated genes, IRF8 and other genes involved in antigen presentation [69]. IL-27 negatively regulated Tr1 cells by induction of metallothioneins (MTs) which in turn reduced stat1 and stat 3 phosphorylation resulting in impaired IL-10 production [70]. Taken together, IL-27 positively regulates both innate and adaptive immune responses.

IL-27 can negatively modulate inflammatory processes. Improved control of Leishmania donovani correlates with massive inflammatory responses were reported in IL-27R-deficient mice [71]. Similarly, WSX-1-/- mice infected with Toxoplasma gondii or Trypanosoma cruzi generated robust IFN-ץ responses and developed lethal $\mathrm{T}$ cell-mediated inflammation [31, 72]. Greater effector and memory CD4+ T cells responses were noted in IL27R lacking mice challenged by Plasmodium berghei [73].

The negative feedback of IL-27 largely depends on the induction of type 1 regulatory $\mathrm{T}$ cells (Tr1). IL-27 can induce Tr1 cells via various mechanisms including activation of Stat1, Stat3 [75-76], upregulation of Blimp1 [77], aryl hydrocarbon receptor (AhR), transcription factor c-Maf, inducible T cell costimulator (ICOS), and IL-21 production, which is indispensable for the expansion and maintenance of Tr1 cells $[34,35]$. Furthermore, the anti-inflammatory effect of IL-27 needs more than the induction of Tr1 cells. IL-27R-/- CD4+ T cells produce more IL-2 than wild-type during in vitro differentiation. The addition of recombinant IL-27 suppressed the expression of IL-2 both transcriptionally and translationally [78]. IL-27 suppresses CD28-mediated IL-2 production by Stat 1 which in turn induces the expression of the suppressor of cytokine signaling 3 (SOCS3) [79]. Moreover, it was observed that WSX-1-deficient macrophages are more efficient in inducing IFN- $\gamma$ and IL-17A production by CD4+ T cells than control. IL-27 can activate stat1 which in turn suppresses cyclooxygenase (COX) expression and followed by reducing prostaglandin (PG2) secretion, which can affect the CD4+ T cell responses [80].

IL-27 was also reported to suppress Th2 cells development and their cytokines production by downregulation of Gata3 and upregulation of T-beta in differentiated Th2 cells [32]. In addition to suppress both Th1 and Th2 cells, IL-27 can inhibit the development of Th17 cells. Consistently, it was demonstrated that IL-27 can inhibit Th17 cell development through various mechanisms including the suppression of IL-6 signaling mediated IL-17 production [33], 
retinoid-related orphan receptor $\gamma(R O R \gamma)$ expression (Th17-specific transcription factor) [36], and also via induction of the IL-10 production [81], and programmed death ligand 1 (PD-L1) on naïve T cells [37]. IL-27 upregulates the expression of Blimp1 in pre-committed Th17 cells and acquired a Tr-1-like phenotype characterized by the production of IL-10 and IFN- $\gamma[77]$.

More recently, it was recognized that IL-27 can inhibit the development of Th9 cells and limit its related encephalitis by mechanism partly depending on Stat-1 [82]. Taken together, IL-27 induces an immunosuppressive effect by both Tr1 cells dependent and independent mechanisms. However, the contribution of IL-27 in the induction of IL-35-producing T regulatory cells remains unknown.

\section{Role of the IL-27 in innate and adaptive immune response to $M t b$ infection}

The innate immunity plays a decisive role in the early clearance of $M t b$ via the recognition of the antigen and subsequent induction of pro-inflammatory cytokines and antimicrobial peptides [83]. The production of IL-27 in response to Mtb infection modulates macrophage responses [41-43]. The combination of IL-12 and anti-IL-27R can limit Mtb growth via upregulation of pro-inflammatory cytokines such as TNF- $\alpha$, IFN- $\gamma$, and IL-18[41, 84]. However, the molecular mechanisms by which IL-27 negatively regulated macrophages during $M t b$ infections remain unclear. It was demonstrated that IL-27R singling in mice peritoneal macrophages suppresses IL-12 and TNF-a production by Stat3 [43]. IL-27 can antagonize IL-18 signaling in human macrophages challenged with $M t b$ by inhibiting the expression of the IL-18 receptor beta-chain and IL-18R downstream signaling component NF-kB [42]. IL-18 and IL-12, synergistically induced IFN- $\gamma$ production by human macrophages and promoted the killing of $M t b$ [84]. It has been shown that IL-27 can inhibit the expression of the phagosomal vacuolar ATPase (V-ATPase) and lysosomal integrated membrane protein-1 (CD63), resulted in the suppression of phagosomal acidification and cathepsin D maturation [85]. IL-27 signaling is necessary for the IL-10 production by macrophages through enhancing the activity and binding of Stat1/Stat3 to the IL-10 promoter [86]. Recently, it was found that IL-10 induced by $M t b$ during macrophage infection can manipulate phagosomal maturation to enhance its own intracellular growth [87]. Most recently a study demonstrated that IL-27 suppresses IFN- $\gamma$ mediated autophagy in human macrophages infected with $M t b$ by inducing autophagy negative regulatory factors $\mathrm{mTOR}$ and $\mathrm{Mcl}-1$ through JAK/PI3-K/Akt and PI3-K pathway, respectively
[88]. In brief, $M t b$ can subvert the normal bactericidal function of macrophages by inducing IL-27 (Figure 2A, Table 1).

Table 1: The consequence of IL-27 signaling in tuberculosis

\begin{tabular}{lll}
\hline $\begin{array}{l}\text { Immune cells } \\
\text { involved }\end{array}$ & Consequence of IL-27 signaling & References \\
\hline Macrophages & $\begin{array}{l}\text { Inhibits the production of pro-inflammatory } \\
\text { cytokines }\end{array}$ & {$[43-42]$} \\
& $\begin{array}{l}\text { Induces the production of anti-inflammatory } \\
\text { cytokine. }\end{array}$ & {$[86]$} \\
& $\begin{array}{l}\text { Inhibits phagosomal acidification. } \\
\text { T cells }\end{array}$ & {$[85,87]$} \\
& $\begin{array}{l}\text { Suppresses the autophagy formation. } \\
\text { Suppresses Th1 cell responses. }\end{array}$ & {$[88]$} \\
& $\begin{array}{l}\text { Induces the IL-10 producing Tr1 cells, pro- } \\
\text { motes proliferation and maintenance of Tr1 }\end{array}$ & {$[34,89-90]$.} \\
& $\begin{array}{l}\text { cells. } \\
\text { Suppresses the Th17 cell development. }\end{array}$ & {$[33,36,36$,} \\
& & $81]$. \\
\hline
\end{tabular}

Ablation of IL-27, either by disruption of the IL-27R gene in mice or by an antibody blockade of the IL-27R, implicates an important role of IL-27 in adaptive immunity against mycobacteria infections. WSX-1-deficient mice have impaired IFN- $\gamma$ production and granuloma formation when challenged with M. bovis BCG [89]. However, there are no differences in liver pathology and bacterial load between mutant and wild type mice [89]. Significant elevation of IL-27 throughout the infanthood and neutralization of IL-27 in neonatal macrophages improved control of bacterial replication [90]. Furthermore, blockade of IL-27 during incubation with the M. bovis (BCG) augmented the IFN- $\gamma$ production by allogeneic CD4+ T cells [90]. Similarly, it has been demonstrated that improved control of $M t b$ growth in the lungs results from increased production of pro-inflammatory cytokines in WSX-1-knockout mice [43]. These results suggest that IL-27 negatively regulated Th1 response (Figure 2B, Table 1), however, the underlying mechanisms remain elusive.

More recently, it was recognized that IL-27 positively regulates IL-10 producing Tr1 cells during chronic inflammation [34, 35, 75-77] (Figure 2B, Table 1). It has been demonstrated that IL-10 suppressed the immune response to $M t b$ infections without immunopathology observed in both C57BL/6 and CBA/J mice [91, 92]. Moreover, it was shown that IL-10-deficient mice were more resistant to $M$. bovis (BCG) challenge in comparison to control mice [93]. Blocking of IL-10R in CBA/J mice improved M. bovis (BCG) evoked protection against $M t b$ characterized by enhanced Th1 and Th17 responses and increased IFN- $y$ and IL-17A production in the mice lungs [94]. Taken together, these data indicate IL-27 can modulate immune response against mycobacteria by inducing IL-10.

IL-27 directly mediated the suppression of the 
development of Th17 cells in chronic inflammation models [33, 36, 37, 81] (Figure 2). Th7 cells induce T cell chemokines (CXCL9, CXCL10 and CXCL11) in the lungs of infected mice to recruit IFN- $\gamma$-producing CD4+ T cells to limit Mtb growth [95]. BCG-induced Th17 cells which can downregulate IL-10 and generate Th1 immune response resulted in protection upon $M t b$ challenge [96]. IL-17-deficient mice were more susceptible to mycobacteria, evidenced by the impaired granulomas formation and decreased IFN- $\gamma$ production [97]. Vaccination will elicit Th17 cells response associated with increased pro-inflammatory cytokines, granulocytes infiltration and severe lung damage in mice [98]. The higher amount of Th17 cells and related cytokines in active tuberculosis patients implicated a role in immunopathogenesis [99, 100].

As an exceptional successful silent killer, $M t b$ can manipulate the host signaling to persist and reactivate at opportune occasion. Knowledge about the emerging player, namely IL-27, will inform better countermeasures against this hideous threat of global health public.

\section{Acknowledgement}

Abu Algasim E Abd Alla is supported by China government scholarship (No. 2013736003) for the PhD degree supervised by Professor Jianping Xie.

This work was supported by the National Natural Science Foundation (grant numbers 81371851, 81071316, 81271882,81301394), New Century Excellent Talents in Universities (grant number NCET-11-0703), National Megaprojects for Key Infectious Diseases (grant number 2008ZX10003-006), Excellent PhD thesis fellowship of Southwest University (grant numbers kb2010017, ky2011003), the Fundamental Research Funds for the Central Universities (Nos. XDJK2011D006， XDJK2012D011， XDJK2012D007， XDJK2013D003 and XDJK2014D040), Natural Science Foundation Project of CQ CSTC (grant number CSTC 2010BB5002), The Chongqing municipal committee of Education for postgraduate excellence program (No.YJG123104), the undergraduate teaching reform program (No. 2011JY052).

\section{Competing Interests}

The authors have declared that no competing interest exists.

\section{Abbreviations:}

IL: Interleukin; IL-27Ra: Interleukin-27 receptor alpha; TCCR: class I cytokine receptor family; gp130: glycoprotein 130; Mtb: Mycobacterium tuberculosis; TIR: Toll-Interleukin receptor; AhR: aryl hydrocarbon receptor; EBI3: Epstein-Barr virus induced gene 3; SNPs: single nucleated polymorphisms; DCs: Dendritic cells;
moDCs: monocyte derived dendritic cells; Th cell: T helper cells; CTL: cytotoxic T lymphocyte; NK cells: Natural Killer cells; Tr1 cells: type 1 regulatory T cells; Tr35 cells: T regulatory type 35 cells; KO: Knockout; APCs: antigen-presenting cells; TLRs: Toll-Like Receptors; IFN: Interferon; Jak: Janus Kinase; Stat: Transcription factor; Tyk: Tyrosine kinase; NF-kB: nuclear factor-kappa beta; MAPK: mitogen activated protein kinase; MyD88: myeloid differentiation factor 88; IRF: IFN regulatory factor; JNK: C-Jun N-terminal kinases; PI3K: phosphoinositide 3-kinase; ICAM-1: intercellular adhesion molecule-1; c-Maf: transcription factor c-Maf; ICOS: inducible T cell costimulator; MIP: Macrophage inflammatory protein; SOCS: Suppressor of cytokine signaling; CD: cathepsin D; mTOR: mammalian target of rapamycin; PI3 K: phosphatidylinositol-3-kinase class I; Mcl-1: Myeloid cell leukemia 1.

\section{References}

1. Team EE. WHO publishes Global tuberculosis report 2013. Eurosurveillance. 2013; 18: 39 .

2. Ehrt S, Schnappinger D. Mycobacterial survival strategies in the phagosome: defence against host stresses. Cellular microbiology. 2009; 11: 1170-8. doi:10.1111/j.1462-5822.2009.01335.x.

3. Flynn JL, Chan J. Immune evasion by Mycobacterium tuberculosis: living with the enemy. Current opinion in immunology. 2003; 15: 450-5.

4. Matucci A, Maggi E, Vultaggio A. Cellular and humoral immune responses during tuberculosis infection: useful knowledge in the era of biological agents. J Rheumatol Supp. 2014; 91: 17-23. doi:10.3899/jrheum.140098.

5. Flynn JL, Chan J. Immunology of tuberculosis. Annu Rev Immunol. 2001; 19: 93-129. doi:10.1146/annurev.immunol.19.1.93.

6. Rojas RE, Balaji KN, Subramanian A, Boom WH. Regulation of human CD4(+) alphabeta T-cell-receptor-positive $(\mathrm{TCR}(+))$ and gammadelta $\mathrm{TCR}(+) \mathrm{T}$-cell responses to Mycobacterium tuberculosis by interleukin-10 and transforming growth factor beta. Infect Immun. 1999; 67: 6461-72.

7. Raja A. Immunology of tuberculosis. The Indian journal of medical research. 2004; 120: 213-32.

8. Tufariello JM, Chan J, Flynn JL. Latent tuberculosis: mechanisms of host and bacillus that contribute to persistent infection. Lancet Infect Dis. 2003; 3: 578-90.

9. Jones LL, Chaturvedi V, Uyttenhove C, Van Snick I, Vignali DA. Distinct subunit pairing criteria within the heterodimeric IL-12 cytokine family. Mol Immunol. 2012; 51: 234-44. doi:10.1016/j.molimm.

10. Sonobe Y, Yawata I, Kawanokuchi J, Takeuchi H, Mizuno T, Suzumura A. Production of IL-27 and other IL-12 family cytokines by microglia and their subpopulations. Brain Res. 2005; 1040: 202-7. doi:10.1016/j.brainres.

11. Pflanz S, Timans JC, Cheung J, Rosales R, Kanzler H, Gilbert J, et al. IL-27, a heterodimeric cytokine composed of EBI3 and p28 protein, induces proliferation of naive CD4+ T cells. Immunity. 2002; 16: 779-90.

12. Li J, Gran B, Zhang GX, Rostami A, Kamoun M. IL-27 subunits and its receptor (WSX-1) mRNAs are markedly up-regulated in inflammatory cells in the CNS during experimental autoimmune encephalomyelitis. J Neurol Sci. 2005; 232: 3-9. doi: $10.1016 /$ j.jns.

13. Pirhonen J, Siren J, Julkunen I, Matikainen S. IFN-alpha regulates Toll-like receptor-mediated IL-27 gene expression in human macrophages. J Leukoc Biol. 2007; 82: 1185-92. doi:Doi 10.1189/Jlb.0307157

14. Liu JG, Guan XQ, Ma XJ. Regulation of IL-27 p28 gene expression in macrophages through MyD88- and interferon-gamma-mediated pathways. J Exp Med. 2007; 204: 141-52. doi:Doi 10.1084/Jem.

15. Zhang J, Qian X, Ning H, Yang J, Xiong H, Liu J. Activation of IL-27 p28 gene transcription by interferon regulatory factor 8 in cooperation with interferon regulatory factor 1. J Biol Chem. 2010; 285: 21269-81. doi:10.1074/jbc.

16. Pflanz S, Timans JC, Cheung J, Rosales R, Kanzler H, Gilbert J, et al. IL-27, a heterodimeric cytokine composed of EBI3 and p28 protein, induces proliferation of naive CD4(+) T cells. Immunity. 2002; 16: 779-90.

17. Yoshida H, Hamano S, Senaldi G, Covey T, Faggioni R, Mu S, et al. WSX-1 is required for the initiation of Th1 responses and resistance to L-major infection. Immunity. 2001; 15: 569-78.

18. Chen Q, Ghilardi N, Wang H, Baker T, Xie MH, Gurney A, et al. Development of Th1-type immune responses requires the type I cytokine receptor TCCR. Nature. 2000; 407: 916-20.

19. Kastelein RA, Hunter CA, Cua DJ. Discovery and biology of IL-23 and IL-27: related but functionally distinct regulators of inflammation. Annu Rev Immunol. 2007; 25: 221-42. doi:10.1146/annurev.immunol. 
20. Guzzo C, Che Mat NF, Gee K. Interleukin-27 induces a STAT1/3- and NF-kappaB-dependent proinflammatory cytokine profile in human monocytes. J Biol Chem. 2010; 285: 24404-11. doi:10.1074/jbc.

21. Hisada M, Kamiya S, Fujita K, Belladonna ML, Aoki T, Koyanagi Y, et al. Potent antitumor activity of interleukin-27. Cancer Res. 2004; 64: 1152-6.

22. Schneider R, Yaneva T, Beauseigle D, El-Khoury L, Arbour N. IL-27 increases the proliferation and effector functions of human naive CD8+ T lymphocytes and promotes their development into Tc1 cells. Eur J Immunol. 2011; 41: 47-59. doi:10.1002/eji.

23. Morishima N, Owaki T, Asakawa M, Kamiya S, Mizuguchi J, Yoshimoto T. Augmentation of effector CD8+ T cell generation with enhanced granzyme B expression by IL-27. J Immunol. 2005; 175: 1686-93.

24. Mittal A, Murugaiyan G, Beynon V, Hu D, Weiner HL. IL-27 induction of IL-21 from human CD8+ T cells induces granzyme B in an autocrine manner. Immunol Cell Biol. 2012; 90: 831-5. doi:10.1038/icb.

25. Liu Z, Liu JQ, Talebian F, Wu LC, Li S, Bai XF. IL-27 enhances the survival of tumor antigen-specific CD8+ T cells and programs them into IL-10-producing, memory precursor-like effector cells. Eur J Immunol. 2013; 43: 468-79. doi:10.1002/eji.

26. Oniki S, Nagai H, Horikawa T, Furukawa J, Belladonna ML, Yoshimoto T, et al. Interleukin-23 and interleukin-27 exert quite different antitumor and vaccine effects on poorly immunogenic melanoma. Cancer Res. 2006; 66: 6395-404. doi:10.1158/0008-5472.CAN-05-4087.

27. Matsui M, Kishida T, Nakano H, Yoshimoto K, Shin-Ya M, Shimada T, et al. Interleukin-27 activates natural killer cells and suppresses NK-resistant head and neck squamous cell carcinoma through inducing antibody-dependent cellular cytotoxicity. Cancer Res. 2009; 69: 2523-30. doi:10.1158/0008-5472.CAN-08-2793.

28. Wei J, Xia S, Sun H, Zhang S, Wang J, Zhao H, et al. Critical role of dendritic cell-derived IL-27 in antitumor immunity through regulating the recruitment and activation of NK and NKT cells. J Immunol. 2013; 191: 500-8. doi:10.4049/jimmunol.

29. Shimizu M, Shimamura M, Owaki T, Asakawa M, Fujita K, Kudo M, et al. Antiangiogenic and antitumor activities of IL-27. J Immunol. 2006; 176: 7317-24.

30. Kachroo P, Lee MH, Zhang L, Baratelli F, Lee G, Srivastava MK, et al. IL-27 inhibits epithelial-mesenchymal transition and angiogenic factor production in a STAT1-dominant pathway in human non-small cell lung cancer. J Exp Clin Cancer Res : CR. 2013; 32: 97

31. Villarino A, Hibbert L, Lieberman L, Wilson E, Mak T, Yoshida H, et al. The IL-27R (WSX-1) is required to suppress $\mathrm{T}$ cell hyperactivity during infection. Immunity. 2003; 19: 645-55.

32. Yoshimoto T, Yoshimoto T, Yasuda K, Mizuguchi J, Nakanishi K. IL-27 suppresses Th2 cell development and Th2 cytokines production from polarized Th2 cells: a novel therapeutic way for Th2-mediated allergic inflammation. J Immunol. 2007; 179: 4415-23.

33. Batten M, Li J, Yi S, Kljavin NM, Danilenko DM, Lucas S, et al. Interleukin 27 limits autoimmune encephalomyelitis by suppressing the development of interleukin 17-producing $\mathrm{T}$ cells. Nat Immunol. 2006; 7: 929-36. doi:10.1038/ni1375.

34. Apetoh L, Quintana FJ, Pot C, Joller N, Xiao S, Kumar D, et al. The aryl hydrocarbon receptor interacts with c-Maf to promote the differentiation of type 1 regulatory T cells induced by IL-27. Nat Immunol. 2010; 11: 854-61.

35. Pot C, Jin H, Awasthi A, Liu SM, Lai CY, Madan R, et al. Cutting edge: IL-27 induces the transcription factor c-Maf, cytokine IL-21, and the costimulatory receptor ICOS that coordinately act together to promote differentiation of IL-10-producing Tr1 cells. J Immunol. 2009; 183: 797-801. doi:10.4049/jimmunol.

36. Diveu C, McGeachy MJ, Boniface K, Stumhofer JS, Sathe M, Joyce-Shaikh B, et al. IL-27 blocks RORc expression to inhibit lineage commitment of Th17 cells. J Immunol. 2009; 182: 5748-56. doi:10.4049/jimmunol.

37. Hirahara K, Ghoreschi K, Yang XP, Takahashi H, Laurence A, Vahedi G, et al. Interleukin-27 priming of $\mathrm{T}$ cells controls IL-17 production in trans via induction of the ligand PD-L1. Immunity. 2012; 36: 1017-30. doi:10.1016/j.immuni.

38. Larousserie F, Pflanz S, Coulomb-L'Hermine A, Brousse N, Kastelein R, Devergne O. Expression of IL-27 in human Th1-associated granulomatous diseases. J Pathol. 2004; 202: 164-71. doi:10.1002/path.1508.

39. Yang WB, Liang QL, Ye ZJ, Niu CM, Ma WL, Xiong XZ, et al. Cell origins and diagnostic accuracy of interleukin 27 in pleural effusions. PLoS One. 2012; 7: e40450. doi:10.1371/journal.pone.

40. Wu YB, Ye ZJ, Qin SM, Wu C, Chen YQ, Shi HZ. Combined detections of interleukin 27, interferon-gamma, and adenosine deaminase in pleural effusion for diagnosis of tuberculous pleurisy. Chin Med J (Engl). 2013; 126: 3215-21.

41. Robinson CM, Nau GJ. Interleukin-12 and interleukin-27 regulate macrophage control of Mycobacterium tuberculosis. J Infect Dis. 2008; 198: 359-66.

42. Robinson CM, O'Dee D, Hamilton T, Nau GJ. Cytokines involved in interferon-gamma production by human macrophages. Journal of innate immunity. 2010; 2: 56-65.

43. Holscher C, Holscher A, Ruckerl D, Yoshimoto T, Yoshida H, Mak T, et al. The IL-27 receptor chain WSX-1 differentially regulates antibacterial immunity and survival during experimental tuberculosis. J Immunol. 2005; 174: 3534-44.

44. Larousserie F, Bardel E, Pflanz S, Arnulf B, Lome-Maldonado C, Hermine O, et al. Analysis of interleukin-27 (EBI3/p28) expression in Epstein-Barr virus- and human T-cell leukemia virus type 1-associated lymphomas: heterogeneous expression of EBI3 subunit by tumoral cells. Am J Pathol. 2005; 166: 1217-28.

45. Devergne O, Coulomb-L'Hermine A, Capel F, Moussa M, Capron F. Expression of Epstein-Barr virus-induced gene 3, an interleukin-12 p40-related molecule, throughout human pregnancy: involvement of syncytiotrophoblasts and extravillous trophoblasts. Am J Pathol. 2001; 159: 1763-76.

46. Devergne O, Hummel M, Koeppen H, Le Beau MM, Nathanson EC, Kieff E, et al. A novel interleukin-12 p40-related protein induced by latent Epstein-Barr virus infection in B lymphocytes. J Virol. 1996; 70: 1143-53.

47. Devergne O, Birkenbach M, Kieff E. Epstein-Barr virus-induced gene 3 and the p35 subunit of interleukin 12 form a novel heterodimeric hematopoietin. Proc Natl Acad Sci U S A. 1997; 94: 12041-6.

48. Collison LW, Vignali DA. Interleukin-35: odd one out or part of the family?. Immunol Rev. 2008; 226: 248-62. doi:10.1111/j.

49. Bazan JF. Haemopoietic receptors and helical cytokines. Immunology today. 1990; 11: 350-4.

50. Tormo AJ, Beaupre LA, Elson G, Crabe S, Gauchat JF. A polyglutamic acid motif confers IL-27 hydroxyapatite and bone-binding properties. J Immunol. 2013; 190: 2931-7. doi:10.4049/jimmunol.

51. Shimozato O, Sato A, Kawamura K, Chiyo M, Ma G, Li Q, et al. The secreted form of p28 subunit of interleukin (IL)-27 inhibits biological functions of IL-27 and suppresses anti-allogeneic immune responses. Immunology. 2009; 128: e816-25. doi:10.1111/j.1365-2567.2009.03088.x.

52. Stumhofer JS, Tait ED, Quinn WJ, 3rd, Hosken N, Spudy B, Goenka R, et al. A role for IL-27p28 as an antagonist of gp130-mediated signaling. Nat Immunol. 2010; 11: 1119-26. doi:10.1038/ni.

53. Chae SC, Li CS, Kim KM, Yang JY, Zhang QG, Lee YC, et al. Identification of polymorphisms in human interleukin-27 and their association with asthma in a Korean population. J Hum Genet. 2007; 52: 355-61.

54. Li CS, Zhang QG, Lee KJ, Cho SW, Lee KM, Hahm KB, et al. Interleukin-27 polymorphisms are associated with inflammatory bowel diseases in a Korean population. J Gastroen Hepatol. 2009; 24: 1692-6.

55. Huang N, Liu L, Wang XZ, Liu D, Yin SY, Yang XD. Association of interleukin (IL)-12 and IL-27 gene polymorphisms with chronic obstructive pulmonary disease in a Chinese population. DNA Cell Biol. 2008; 27: 527-31. doi:10.1089/dna.

56. Zhang Z, Zhou B, Wu Y, Gao Q, Zhang K, Song Y, et al. Prognostic value of IL-27 polymorphisms and the susceptibility to epithelial ovarian cancer in a Chinese population. Immunogenetics. 2014; 66: 85-92.

57. Zhang J, Qian X, Ning H, Eickhoff CS, Hoft DF, Liu J. Transcriptional suppression of IL-27 production by Mycobacterium tuberculosis-activated p38 MAPK via inhibition of AP-1 binding. J Immunol. 2011; 186: 5885-95. doi:10.4049/jimmunol

58. Molle C, Nguyen M, Flamand V, Renneson J, Trottein F, De Wit D, et al. IL-27 synthesis induced by TLR ligation critically depends on IFN regulatory factor 3. J Immunol. 2007; 178: 7607-15.

59. Wirtz S, Becker C, Fantini MC, Nieuwenhuis EE, Tubbe I, Galle PR, et al. EBV-induced gene 3 transcription is induced by TLR signaling in primary dendritic cells via NF-kappa B activation. J Immunol. 2005; 174: 2814-24.

60. Blahoianu MA, Rahimi AA, Kozlowski M, Angel JB, Kumar A. IFN-gamma-induced IL-27 and IL-27p28 expression are differentially regulated through JNK MAPK and PI3K pathways independent of Jak/STAT in human monocytic cells. Immunobiology. 2014; 219: 1-8. doi:10.1016/j.imbio.

61. Hibbert L, Pflanz S, Malefyt RD, Kastelein RA. IL-27 and IFN-alpha signal via Stat 1 and Stat 3 and induce T-Bet and IL-12R beta 2 in naive T cells. J Interf Cytok Res. 2003; 23: 513-22

62. Kamiya S, Owaki T, Morishima N, Fukai F, Mizuguchi J, Yoshimoto T. An indispensable role for STAT1 in IL-27-induced T-bet expression but not proliferation of naive CD4+ T cells. J Immunol. 2004; 173: 3871-7.

63. Lucas S, Ghilardi N, Li J, de Sauvage FJ. IL-27 regulates IL-12 responsiveness of naive $\mathrm{CD} 4+\mathrm{T}$ cells through Stat1-dependent and -independent mechanisms. Proc Natl Acad Sci U S A. 2003; 100: 15047-52. doi:10.1073/pnas.

64. Pflanz S, Hibbert L, Mattson J, Rosales R, Vaisberg E, Bazan JF, et al. WSX-1 and glycoprotein 130 constitute a signal-transducing receptor for IL-27. J Immunol. 2004; 172: 2225-31.

65. Takeda A, Hamano S, Yamanaka A, Hanada T, Ishibashi T, Mak TW, et al. Cutting edge: role of IL-27/WSX-1 signaling for induction of T-bet through activation of STAT1 during initial Th1 commitment. J Immunol. 2003; 170: 4886-90.

66. Mayer KD, Mohrs K, Reiley W, Wittmer S, Kohlmeier JE, Pearl JE, et al. Cutting edge: T-bet and IL-27R are critical for in vivo IFN-gamma production by CD8 T cells during infection. J Immunol. 2008; 180: 693-7.

67. Guzzo C, Ayer A, Basta S, Banfield BW, Gee K. IL-27 enhances LPS-induced proinflammatory cytokine production via upregulation of TLR4 expression and signaling in human monocytes. J Immunol. 2012; 188: 864-73. doi:10.4049/jimmunol.

68. Shimizu M, Ogura K, Mizoguchi I, Chiba Y, Higuchi K, Ohtsuka H, et al. IL-27 promotes nitric oxide production induced by LPS through STAT1, NF-kappaB and MAPKs. Immunobiology. 2013; 218: 628-34. doi:10.1016/j.imbio.

69. Birkholz J, Doganci A, Darstein C, Gehring S, Zepp F, Meyer CU. IL-27 improves migrational and antiviral potential of $\mathrm{CB}$ dendritic cells. Hum Immunol. 2014. doi:10.1016/j.humimm.

70. Wu C, Pot C, Apetoh L, Thalhamer T, Zhu B, Murugaiyan G, et al Metallothioneins negatively regulate IL-27-induced type 1 regulatory T-cell differentiation. Proc Natl Acad Sci U S A. 2013; 110: 7802-7. doi:10.1073/pnas. 
71. Rosas LE, Satoskar AA, Roth KM, Keiser TL, Barbi J, Hunter C, et al. Interleukin-27R (WSX-1/T-cell cytokine receptor) gene-deficient mice display enhanced resistance to leishmania donovani infection but develop severe liver immunopathology. Am J Pathol. 2006; 168: 158-69. doi:10.2353/ajpath.

72. Hamano S, Himeno K, Miyazaki Y, Ishii K, Yamanaka A, Takeda A, et al. WSX-1 is required for resistance to Trypanosoma cruzi infection by regulation of proinflammatory cytokine production. Immunity. 2003; 19: 657-67.

73. Gwyer Findlay E, Villegas-Mendez A, O'Regan N, de Souza JB, Grady LM, Saris CJ, et al. IL-27 receptor signaling regulates memory CD4+ T cell populations and suppresses rapid inflammatory responses during secondary malaria infection. Infect Immun. 2014; 82: 10-20.

74. Findlay EG, Greig R, Stumhofer JS, Hafalla JC, de Souza JB, Saris CJ, et al. Essential role for IL-27 receptor signaling in prevention of Th1-mediated immunopathology during malaria infection. J Immunol. 2010; 185: 2482-92. doi:10.4049/jimmunol.

75. Hall AO, Silver JS, Hunter CA. The immunobiology of IL-27. Adv Immunol. 2012; 115: 1-44.

76. Wang H, Meng R, Li Z, Yang B, Liu Y, Huang F, et al. IL-27 induces the differentiation of Tr1-like cells from human naive CD4+ $T$ cells via the phosphorylation of STAT1 and STAT3. Immunol Lett. 2011; 136: 21-8. doi:10.1016/j.imlet.

77. Heinemann C, Heink S, Petermann F, Vasanthakumar A, Rothhammer V, Doorduijn E, et al. IL-27 and IL-12 oppose pro-inflammatory IL-23 in CD4+ T cells by inducing Blimp1. Nat Commun. 2014; 5: 3770. doi:10.1038/ncomms4770.

78. Villarino AV, Stumhofer JS, Saris CJ, Kastelein RA, de Sauvage FJ, Hunter CA. IL-27 limits IL-2 production during Th1 differentiation. J Immunol. 2006; 176: 237-47.

79. Owaki T, Asakawa M, Kamiya S, Takeda K, Fukai F, Mizuguchi J, et al. IL-27 suppresses CD28-mediated [correction of medicated] IL-2 production through suppressor of cytokine signaling 3. J Immunol. 2006; 176: 2773-80.

80. Sato Y, Hara H, Okuno T, Ozaki N, Suzuki S, Yokomizo T, et al. IL-27 affects helper T cell responses via regulation of PGE2 production by macrophages. Biochem Biophys Res Commun. 2014; 451: 215-21. doi:10.1016/j.bbrc.

81. Fitzgerald DC, Ciric B, Touil T, Harle H, Grammatikopolou J, Das Sarma J, et al. Suppressive effect of IL-27 on encephalitogenic Th17 cells and the effector phase of experimental autoimmune encephalomyelitis. J Immunol. 2007; 179: 3268-75.

82. Murugaiyan G, Beynon V, Pires Da Cunha A, Joller N, Weiner HL. IFN-gamma limits Th9-mediated autoimmune inflammation through dendritic cell modulation of IL-27. J Immunol. 2012; 189: 5277-83. doi:10.4049/jimmunol.

83. Yuk JM, Jo EK. Host immune responses to mycobacterial antigens and their implications for the development of a vaccine to control tuberculosis. Clin Exp Vaccine Res. 2014; 3: 155-67. doi:10.7774/cevr.

84. Robinson CM, Jung JY, Nau GJ. Interferon-gamma, tumor necrosis factor, and interleukin-18 cooperate to control growth of Mycobacterium tuberculosis in human macrophages. Cytokine. 2012; 60: 233-41. doi:10.1016/j.cyto.

85. Jung JY, Robinson CM. IL-12 and IL-27 regulate the phagolysosomal pathway in mycobacteria-infected human macrophages. Cell Commun Signal. 2014; 12: 16.

86. Iyer SS, Ghaffari AA, Cheng G. Lipopolysaccharide-mediated IL-10 transcriptional regulation requires sequential induction of type I IFNs and IL-27 in macrophages. J Immunol. 2010; 185: 6599-607. doi:10.4049/jimmunol.

87. O'Leary S, O'Sullivan MP, Keane J. IL-10 blocks phagosome maturation in mycobacterium tuberculosis-infected human macrophages. Am J Respir Cell Mol Biol. 2011; 45: 172-80. doi:10.1165/rcmb

88. Sharma G, Dutta RK, Khan MA, Ishaq M, Sharma K, Malhotra H, et al. IL-27 inhibits IFN-gamma induced autophagy by concomitant induction of JAK/PI3 $\mathrm{K} / \mathrm{Akt} / \mathrm{mTOR}$ cascade and up-regulation of Mcl-1 in Mycobacterium tuberculosis H37Rv infected macrophages. Int J Biochem Cell Biol. 2014. doi:10.1016/j.biocel

89. Yoshida H, Hamano S, Senaldi G, Covey T, Faggioni R, Mu S, et al. WSX-1 is required for the initiation of Th1 responses and resistance to L. major infection. Immunity. 2001; 15: 569-78.

90. Kraft JD, Horzempa J, Davis C, Jung JY, Pena MM, Robinson CM. Neonatal macrophages express elevated levels of interleukin-27 that oppose immune responses. Immunology. 2013; 139: 484-93. doi:10.1111/imm.

91. Turner J, Gonzalez-Juarrero M, Ellis DL, Basaraba RJ, Kipnis A, Orme IM, et al. In vivo IL-10 production reactivates chronic pulmonary tuberculosis in C57BL/ 6 mice. J Immunol. 2002; 169: 6343-51.

92. Beamer GL, Flaherty DK, Assogba BD, Stromberg P, Gonzalez-Juarrero M, de Waal Malefyt R, et al. Interleukin-10 promotes Mycobacterium tuberculosis disease progression in CBA/J mice. J Immunol. 2008; 181: 5545-50.

93. Murray PI, Young RA. Increased antimycobacterial immunity in interleukin-10-deficient mice. Infect Immun. 1999; 67: 3087-95.

94. Pitt JM, Stavropoulos E, Redford PS, Beebe AM, Bancroft GJ, Young DB, et al. Blockade of IL-10 signaling during bacillus Calmette-Guerin vaccination enhances and sustains Th1, Th17, and innate lymphoid IFN-gamma and IL-17 responses and increases protection to Mycobacterium tuberculosis infection. J Immunol. 2012; 189: 4079-87. doi:10.4049/jimmunol.1201061.

95. Khader SA, Bell GK, Pearl JE, Fountain JJ, Rangel-Moreno J, Cilley GE, et al. IL-23 and IL-17 in the establishment of protective pulmonary CD4+ T cell responses after vaccination and during Mycobacterium tuberculosis challenge. Nat Immunol. 2007; 8: 369-77. doi:10.1038/ni1449.
96. Gopal R, Lin Y, Obermajer N, Slight S, Nuthalapati N, Ahmed M, et al. IL-23-dependent IL-17 drives Th1-cell responses following Mycobacterium bovis BCG vaccination. Eur J Immunol. 2012; 42: 364-73. doi:10.1002/eji.

97. Umemura M, Yahagi A, Hamada S, Begum MD, Watanabe H, Kawakami K, et al. IL-17-mediated regulation of innate and acquired immune response against pulmonary Mycobacterium bovis bacille Calmette-Guerin infection. J Immunol. 2007; 178: 3786-96.

98. Cruz A, Fraga AG, Fountain JJ, Rangel-Moreno J, Torrado E, Saraiva M, et al. Pathological role of interleukin 17 in mice subjected to repeated BCG vaccination after infection with Mycobacterium tuberculosis. J Exp Med. 2010; 207: 1609-16. doi:10.1084/jem.

99. Jurado JO, Pasquinelli V, Alvarez IB, Pena D, Rovetta AI, Tateosian NL, et al. IL-17 and IFN-gamma expression in lymphocytes from patients with active tuberculosis correlates with the severity of the disease. J Leukoc Biol. 2012; 91: 991-1002. doi:10.1189/jlb.

100. Wang GQ, Yang CL, Yue DF, Pei LH, Zhong H, Niu JX. The changes and its significance of Th17 and Treg cells and related cytokines in patients with tuberculosis pleurisy. Allergy Asthma Clin Immunol. 2014; 10: 28. 